This item was submitted to Loughborough's Research Repository by the author.

Items in Figshare are protected by copyright, with all rights reserved, unless otherwise indicated.

\title{
Musical distinctions in England - Understanding cultural homology and omnivourism through a methods comparison
}

PLEASE CITE THE PUBLISHED VERSION

https://doi.org/10.1177/0759106315572563

\section{PUBLISHER}

SAGE Publications $@$ C The Author

VERSION

AM (Accepted Manuscript)

\section{PUBLISHER STATEMENT}

This work is made available according to the conditions of the Creative Commons Attribution-NonCommercialNoDerivatives 4.0 International (CC BY-NC-ND 4.0) licence. Full details of this licence are available at: https://creativecommons.org/licenses/by-nc-nd/4.0/

\section{LICENCE}

CC BY-NC-ND 4.0

\section{REPOSITORY RECORD}

Leguina, Adrian. 2019. "Musical Distinctions in England - Understanding Cultural Homology and Omnivourism Through a Methods Comparison”. figshare. https://hdl.handle.net/2134/31937. 


\title{
Musical distinctions in England - Understanding cultural homology and omnivourism through a methods comparison
}

\author{
Adrian Leguina \\ Institute for Social Change, The University of Manchester \\ Bulletin de Methodologie Sociologique 2015, Vol. 126(1) 28-45 \\ Reprints and permission: \\ sagepub.com/journalsPermissions.nav \\ DOI: $10.1177 / 0759106315572563$ \\ bms.sagepub.com
}

\begin{abstract}
P. Bourdieu's homology thesis and R. A. Peterson's cultural omnivourism have particularly captured the attention of scholars on cultural stratification. Research has supported one hypothesis, the other, or both simultaneously. Meanwhile, a question remains unanswered: do different statistical methods offer consistent results? This article reviews and compares several methodological frameworks published over the last 30 years. The wide range of alternatives has sometimes generated contradictory results. English musical taste and distaste indicators from the Cultural Capital and Social Exclusion project (CCSE) are analysed. Through direct comparison of statistical methods, it is demonstrated that results are consistent and complementary. Moreover, it is argued that there is no ideal methodological blueprint.
\end{abstract}

Keywords: Musical Taste, Homology, Omnivourism, Methods Comparison

\subsection{Introduction}

The processes and mechanisms by which contemporary societies are symbolically stratified through cultural engagement have been theorised from several different perspectives. However, during the late twentieth century two major works on the social stratification of culture captured the attention of researchers: P. Bourdieu's homology thesis and R. A. Peterson's cultural omnivourism. A large body of research has reported results worldwide, supporting one hypothesis or another or simultaneously both. It has addressed a wide variety of cultural domains, analysing data containing various types of cultural indicators under several operationalisations and statistical methods. The main objective of this article is to offer a review of several methodological frameworks proposed to study the relationship between social stratification and musical taste. A second aim is to show to what extent results from different methodological approaches are consistent. To accomplish this, it is illustrated 
how homology and omnivourism are tested under several operationalisations and methods proposed by the most salient research published over the last 30 years.

This article examines data obtained from the Cultural Capital and Social Exclusion project (CCSE), a national study specifically designed to enable the study of cultural consumption (Thomson, 2004; Bennett et al., 2009). The sample comes from a probabilistic cross-sectional design, taken between winter 2004 and early spring of 2005 and is representative of adults aged 18+ from England, Wales and Scotland. Due to the reduced amount of missing values, and following the common practice in the literature, 10 observations with missing values were excluded from the analysis ${ }^{1}$. Only the English subsample is analysed, amounting to an effective sample size of 1,269 individuals. Appendices 1,2 and 3 show the eight musical genres analysed on a seven-point gradational scale and recoded as a like-neutral-dislike trichotomy (A.1). In accordance with proposed operationalisations, these indicators are also coded as volume of preferences (A.2) and hierarchically ordered according to the Warde and Gayo-Cal (2009) rank (A.3). The authors calculated for each genre (as well as for the entire sample and three age cohorts) a legitimacy ratio as the 'percentage of university graduates liking divided by the percentage of those with no qualification liking' (Warde and Gayo-Cal, 2009: 127). Legitimate genres are those that are more than twice as often preferred by graduates. Unauthorised are those less frequently liked by graduates than the rest of the sample (ratio less than 1) and the remainder are common. Thus the categories are as follows: legitimate: classical; common: heavy metal, modern jazz, rock and world music; unauthorised: country and western, electronic and urban, which coincide respectively with the Purhonen, Gronow and Rahkonen (2010) high, middle and lowbrow classification. In order to simplify analysis and facilitate comparison between techniques, only some of the most frequently studied sociodemographic variables in the literature were included, such as age, sex, social class and education ${ }^{2}$ (Appendix 4). Some of the most relevant studies are briefly described below ${ }^{3}$. To contextualise this comparison, each framework is presented alongside the statistical techniques, which have traditionally been used to test it. This

\footnotetext{
${ }^{1}$ Exceptions are the application of EM algorithm and multiple imputation found in Tampubolon (2008a, b, 2010).

${ }^{2}$ No education: CASMIN $1 \mathrm{a}+1 \mathrm{~b}$; Secondary basic/intermediate: CASMIN $1 \mathrm{c}+2 \mathrm{a}+2 \mathrm{~b}$; Secondary complete: CASMIN 2c vocational + 2c general; Lower tertiary: CASMIN 3a; Upper tertiary: CASMIN 3b (Brauns, Scherer and Steinmann, 2003).

${ }^{3}$ For a comprehensive theoretical review of the subject see Peterson (2005), Bennett et al. (2009), Warde and Gayo-Cal (2009) and Coulangeon and Lemel (2010a).
} 
selection is not comprehensive, but covers the most prominent works and the most commonly applied methodologies in the literature.

\subsection{Homology}

Briefly, Bourdieu's theoretical approach stands on two key concepts: structural homology and habitus $^{4}$. According to this framework, homology between the space aesthetic preferences and that of social class structures is mediated by habitus (Bourdieu, 1984). An important assumption derived from habitus is the unity of tastes, which implies distinction among classes in terms of their sets of cultural activities. This occurs within fields, where individuals are socially positioned and where struggles - symbolic violence - take place (Bourdieu and Wacquant, 1992). In addition to habitus, people during their life accumulate capitals, which are species of power allowing certain profits to be obtained (Bourdieu and Wacquant, 1992). The resulting multidimensional space is therefore a reflection of volume and a composition of capitals. Consequently, members of the upper social classes tend to prefer more sophisticated and 'difficult' cultural forms which the middle class (or petit bourgeoisie) aspires to and imitates while at the same time struggling to differentiate themselves from the dominated lower social classes, who tend to passively prefer simplistic and repetitive cultural items. Briefly, the homology hypothesis might be stated as follows:

$\boldsymbol{H}_{1}$ : Social stratification axes are highly correlated with lifestyles (Bourdieu, 1984; Tampubolon 2008a; Bennett et al., 2009; Coulangeon and Lemel, 2010a). Specifically, higher (lower) social positions tend to prefer (reject) what are traditionally accepted as highbrow musical genres, while lower (higher) social positions prefer (reject) lowbrow.

Bourdieu argued that quantitative analysis tools in sociology must be multidimensional and relational, and should not reduce variable interrelations into dependent-independent hierarchies (Bourdieu, 1984). In consequence, correspondence analysis and multiple correspondence analysis (MCA) are considered to be the most appropriate methods to understand social reality (Bourdieu and Wacquant, 1992; Rouanet et al., 2000; Lebaron, 2010). MCA is a multivariate technique used to analyse categorical data, structured as Individuals x variables tables.

\footnotetext{
4 ، ... both the generative principle of objectively classifiable judgments and the system of classification (...) of these practices. It is in the relationship between the two capacities which define the habitus, the capacity to produce classifiable practices and works, and the capacity to differentiate and appreciate these practices and products (taste), that represented social world...' (Bourdieu, 1984:170).
} 


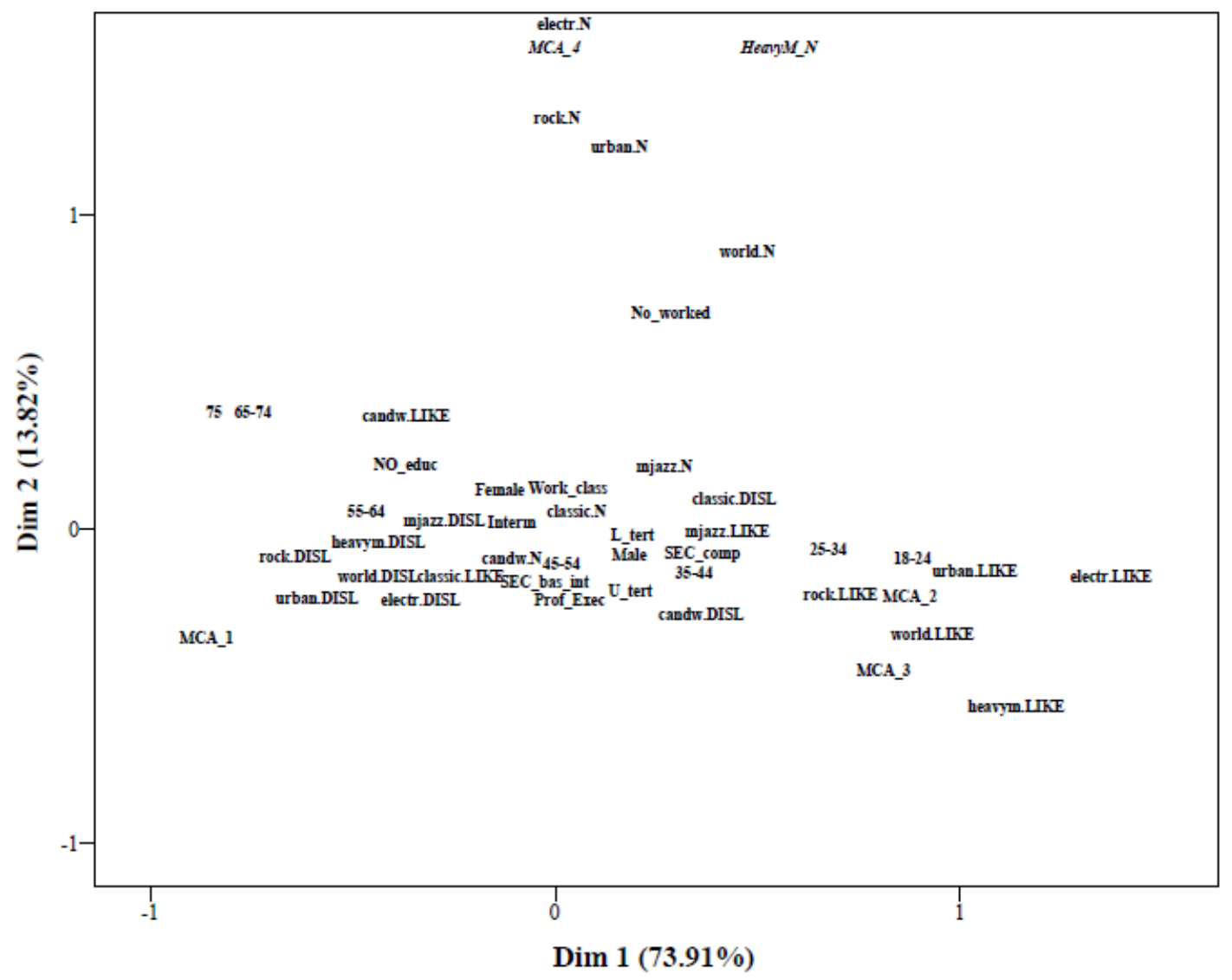

Figure Error! No text of specified style in document..1. MCA first and second dimensions - Musical indicators and supplementary variables.

Genre labels: Classical (classic), Heavy metal (heavym), Modern jazz (mjazz), Rock (rock), World music (world), Country and western (candw), Electronic (electr), Urban (urban). Taste labels: Like (LIKE), Neutral (N), Dislike (DISL).

The objective is the dimension reduction, providing summary values which can be plotted as clouds to visualise interrelations among individuals and categorical variables. Supplementary individuals and variables may be included to aid interpretation of results (Le Roux and Rouanet, 2004). This technique was applied to indicators of musical taste recoded as categorical variables (like, neutral, dislike), using the package FactoMineR (Lê et al., 2008), part of the R statistical software (R Core Team, 2013). Inspecting the modified explained percentages of variance (Le Roux and Rouanet, 2004), it was decided to retain the first three dimensions; these explain over 98 percent of the modified cloud variance (31.47 percent of original variance). Figures 2.1 and 2.2 represent how musical likes and dislikes are interrelated. 


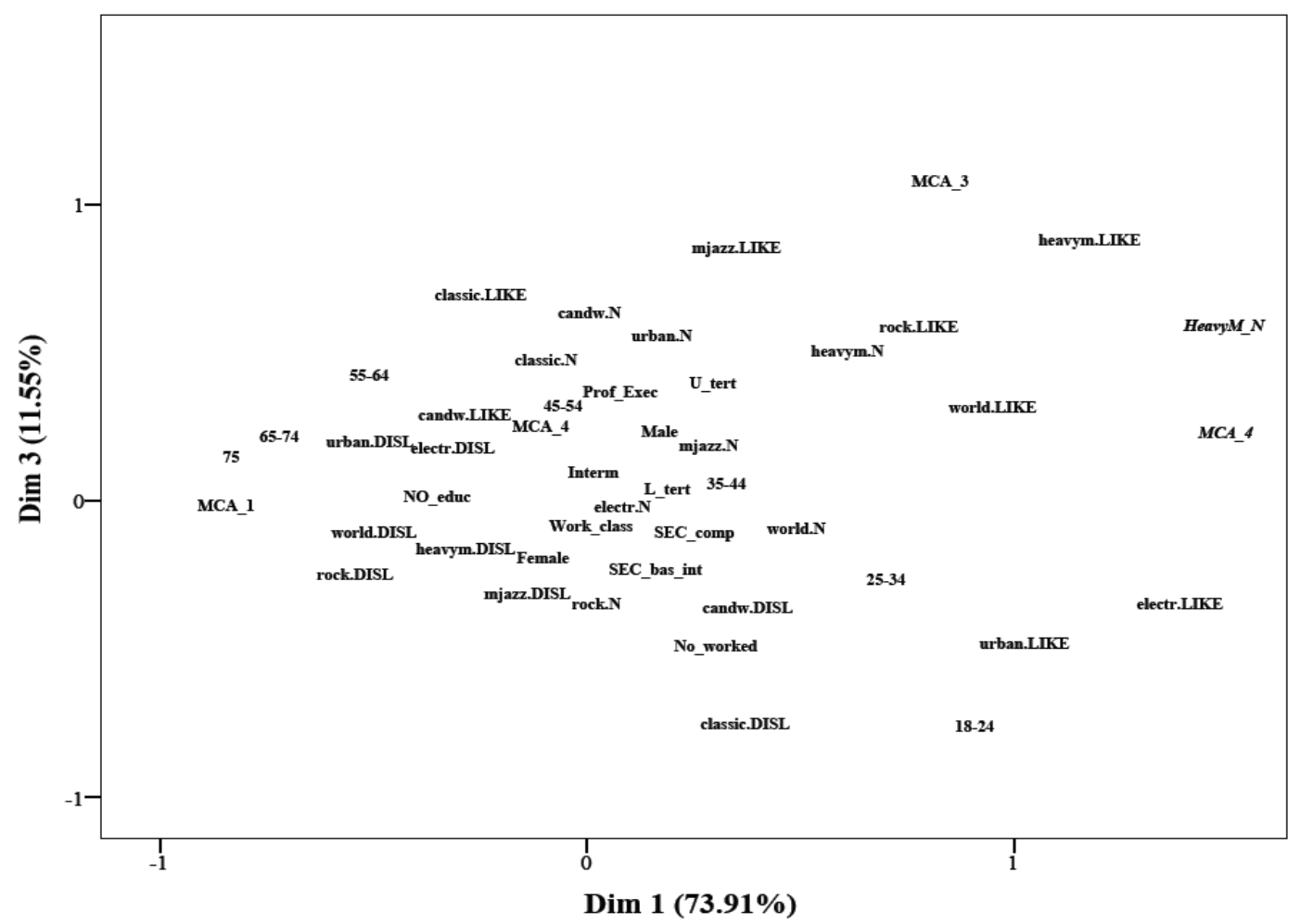

Figure Error! No text of specified style in document..2. MCA first and third dimensions - Musical indicators and supplementary variables

Genre labels: Classical (classic), Heavy metal (heavym), Modern jazz (mjazz), Rock (rock), World music (world), Country and western (candw), Electronic (electr), Urban (urban). Taste labels: Like (LIKE), Neutral (N), Dislike (DISL).

The first dimension shows tensions between individuals reporting like of electronic, urban, heavy metal, rock, and world music, in contrast to the ones declaring dislike of these but preferring country and western, and classical music. The second dimension distinguishes individuals who claim to be neutral to electronic, urban, heavy metal, rock, and world music. Finally, the third dimension reflects tensions between liking modern jazz, rock, classical, and heavy metal and dislike of these while liking urban and electronic music. Then we superimpose the four explanatory variables on our cultural map as supplementary and we calculate how much of the axis variance each variable explains $\left(R^{2}\right)$ through one-way ANOVAs, one of the tools to describe MCA results available on FactoMineR. We conclude that age is the most important structuring variable of musical taste across the first dimension, followed by educational level. The second dimension is related to class and education; these variables also appear across the third dimension, where differentiation is again predominantly age. 
Next, hierarchical cluster analysis is applied (Le Roux and Rouanet, 2004). The objective is to understand whether there are distinct groups based on musical taste patterns and if so, to describe them in socioeconomic terms. It was decided to retain four clusters as the final solution. The decision was made inspecting graphical outputs such as dendograms and MCA confidence ellipses (Le Roux and Rouanet, 2004) for different settings. The largest detected group is labelled as $\boldsymbol{M C A}_{\mathbf{1}}$ (41.8 percent of the sample), which exhibits a preference for classical, and country and western but rejects urban, electronic and rock. This group is mainly composed by adult (over 35 years old), women, and individuals with low and intermediate levels of education. A second group, $\boldsymbol{M C A _ { 2 }}$ (20.5 percent of the sample), likes electronic, urban, and to a lesser extent rock and world music. They dislike the preferences of the previous group. Its members are mainly from younger age cohorts (25-34 years old), the working class, and individuals who having attained secondary and post-secondary education. A third group, $\boldsymbol{M C A}_{3}$ (24.3 percent of the sample), shows a preference for the greatest number of genres (including rock, jazz, classical, and world music), running alongside higher tolerance to heavy metal. Its members are mainly from the sample of middle-aged (36-54 years old), men, and individuals who having attained the highest levels of education and social class. Finally, a fourth group, $\boldsymbol{M C A}_{\mathbf{4}}$ (13.3 percent of the sample), holds neutral opinions on genres that the $\boldsymbol{M C \boldsymbol { A } _ { 2 }}$ group likes and which $\boldsymbol{M C \boldsymbol { A } _ { 1 }}$ rejects. They tend to be adults (over 55 years old), with low educational level and from the working class. There is an indication that rejection of different genres by the various detected taste groups is based on social position. Simultaneously, we observe that the $\boldsymbol{M C A}_{\mathbf{3}}$ group appears to be able to cross cultural boundaries, and further, they might tend to behave like cultural omnivores, which we discuss below. It is therefore possible to observe simultaneously evidence of the homology hypothesis $\left(\boldsymbol{H}_{\mathbf{1}}\right)$, and different forms of cultural omnivourism.

\subsection{Omnivourism}

The influential work of Peterson and Simkus (1992) offered evidence of an alternative trend, in which cultural engagement works as a status marker in the USA. This idea, named cultural omnivourism, might be defined as the opposition between individuals from higher social positions who simultaneously prefer several highbrow and lowbrow musical genres (omnivores), and individuals from lower positions who preferred one or few lowbrow genres (univores) (Peterson, 1992; Peterson and Simkus, 1992). Subsequently, refined conceptualisations have been developed. Warde, Wright and Gayo-Cal (2007) argue that reference to the cultural omnivore as an explanation of contemporary cultural engagement is 
not straightforward, and propose to differentiate between omnivore by volume and by composition. The former may be defined as a cumulative scale of genres, which people like, while the latter is a matter of crossing symbolic boundaries and may be defined as a comparison of typologies of preferences that measure their breadth.

\subsubsection{By volume}

Peterson and Kern (1996) produced the first work that provided an empirical definition of an overall trend of omnivourism. They measured tendency to be a cultural omnivore by the amount of low and middlebrow musical genres that respondents chose, dividing the sample between highbrows (people who choose both classical music and opera and strongly like one of these) and others (people who do not select highbrow musical genres). Linear regression models by ordinary least square (OLS) are then applied to test the impact of sociodemographic variables on amount of likes. Linear regression is a statistical model in which a numerical continuous (dependent) variable is predicted by a set of numerical or categorical (independent) variables. Ordinary least square (OLS) is a method used to estimate regression coefficients (Long, 1997).

Similarly Warde, Wright and Gayo-Cal (2008), Warde and Gayo-Cal (2009) and Purhonen, Gronow and Rahkonen (2010) applied means comparison and Poisson regression to test omnivourism by volume, but using the raw number of preferences and participation. This is a statistical model in which a numerical counting (dependent) variable is predicted by a set of numerical or categorical (independent) variables (Long, 1997). Therefore, an omnivore by volume hypothesis might be stated thus:

$\boldsymbol{H}_{2}$ : The higher the respondent's social position, the higher the volume of musical genres the respondent likes (Warde, Wright and Gayo-Cal, 2008; Warde and GayoCal, 2009; Purhonen et al., 2010). Individuals who prefer legitimate music are more likely to prefer other non-legitimate genres (Peterson and Kern, 1996).

The sample is divided into those with 'legitimate' likes and those without. In this case, 'legitimate' means whether or not respondents like classical music. Next, linear regression was implemented using SPSS Statistics version 20 (IBM Corp, 2011). In relation to the raw number of likes, regardless of whether respondents like classical or not (first two columns table 2.1), there is a negative effect of age; if respondents do not like classical there is an additional negative effect of being female and having attained basic or intermediate secondary level education. 
Table Error! No text of specified style in document..1. Omnivore by volume linear regressions.

\begin{tabular}{ccccccc}
\hline & & \# likes $(\boldsymbol{\beta})$ & \multicolumn{2}{c}{$\#$ common likes $(\boldsymbol{\beta})$} & \multicolumn{2}{c}{ unauth likes $(\boldsymbol{\beta})$} \\
& Legit taste & No legit taste & Legit taste & No legit taste & Legit taste & No legit taste \\
\hline Sec bas/int & -.214 & $-.278^{*}$ & -.093 & -.070 & -.128 & $-.207 *$ \\
Full sec & .296 & .016 & .101 & $.270^{*}$ & .207 & $-.254^{*}$ \\
L tert & -.194 & -.259 & .056 & .133 & $-.243^{*}$ & $-.392^{* * *}$ \\
U tert ${ }^{1}$ & .056 & -.039 & .156 & $.286^{*}$ & -.101 & $-.329 * *$ \\
Never work & -.949 & -.233 & -.490 & -.023 & -.313 & -.209 \\
Interm & -.042 & .059 & .016 & .045 & -.048 & .015 \\
Prof. exec & -.246 & .221 & -.056 & $.230 *$ & $-.184 *$ & -.012 \\
Female & -.205 & $-.491 * * *$ & $-.234 * *$ & $-.456 * * *$ & .026 & -.039 \\
Age & $-.072 * *$ & $-.034 *$ & -.026 & .017 & $-.046 * * *$ & $-.051 * * *$ \\
Age^2 & $3 \mathrm{E}-04$ & $4 \mathrm{E}-05$ & $-3 \mathrm{E}-05$ & $-3 \mathrm{E}-04 * *$ & $3 \mathrm{E}-04 * *$ & $.4 \mathrm{E}-04 * * *$ \\
Intercept $^{3}$ & $6.064 * * *$ & $3.650 * * *$ & $2.764 * * *$ & $1.089 * * *$ & $2.273 * * *$ & $2.568 * * *$ \\
\hline $\mathrm{R}^{\wedge} 2$ & $20.9 \%$ & $16.1 \%$ & $24.4 \%$ & $17.3 \%$ & $7.9 \%$ & $11.4 \%$ \\
\hline
\end{tabular}

Ref. cats: 1: No educational qualifications; 2: working class; 3: Male.

Sig levels: $* \mathrm{p}<0.05, * * \mathrm{p}<0.01, * * * \mathrm{p}<0.001$ (two tailed tests)

In addition, volumes of common and unauthorised likes are used as dependent variables. Results are presented in the last four columns of Table 1. Regardless of whether respondents like classical or not, being female decreases the amount of common likes. In the case of having no taste for classical, there are positive impacts of high educational level and social class. That is, people who have no legitimate taste but occupy higher positions of the social hierarchy tend to display more common tastes. Regarding the volume of unauthorised likes, if respondents like classical music there is a negative impact of post-secondary education, higher social class and, according to age squared term, a negatively declining effect of age. However, if a respondent reports not liking classical, there is a concomitant negative effect of educational level and again, there is a positive declining effect of age. In summary, results show affirmative evidence regarding the homology hypothesis but only partial support to that of omnivore by volume. Liking classical music does not seem to increase the number of common and unauthorised preferences, which could be interpreted as rejection. For individuals who do not like classical music, higher educational level and social class positively impact on volume of common tastes.

Bryson (1996) builds an exclusiveness scale, which counts the amount of genres that people 'dislike' and 'dislike very much'. Amount of dislikes is the dependent variable for OLS linear regressions. Similarly, Warde, Wright and Gayo-Cal (2008) compare the amount of dislikes 
between omnivores and non-omnivores. An alternative 'omnivore by volume' hypothesis might therefore be stated as:

$\boldsymbol{H}_{3}$ : The lower the respondent's social position, the higher the amount of musical genres the respondent dislikes (Bryson, 1996).

Different types of regression model most commonly used to analyse count data are applied to test the impact of stratification variables on the amount of likes and dislikes. Instead of selecting one technique, we applied linear, Poisson and negative binomial regression, using number of likes and dislikes as dependent variables. The latter might be understood as a generalisation of Poisson regression, allowing analysis of over-dispersed count variables (high proportion of zeros) (Long, 1997). Due to differing specifications, estimated parameters are not directly comparable among models; we therefore focus on coefficients significance (table 2.2).

Table Error! No text of specified style in document..2. Different regression models to test omnivore by volume.

\begin{tabular}{|c|c|c|c|c|c|c|}
\hline & \multirow[b]{2}{*}{$\begin{array}{l}\text { Volume of } \\
\text { likes }\end{array}$} & \multicolumn{2}{|c|}{ Linear regression $(\beta)$} & Poisson regression ( $\beta$ ) & \multicolumn{2}{|c|}{ Negative binomial $(\beta)$} \\
\hline & & $\begin{array}{c}\text { Volume of } \\
\text { dislikes }\end{array}$ & $\begin{array}{c}\text { Volume of } \\
\text { likes }\end{array}$ & $\begin{array}{c}\text { Volume of } \\
\text { dislikes }\end{array}$ & $\begin{array}{c}\text { Volume of } \\
\text { likes }\end{array}$ & $\begin{array}{c}\text { Volume of } \\
\text { dislikes }\end{array}$ \\
\hline Sec bas/int & -.126 & .142 & -.048 & .031 & -.059 & .031 \\
\hline Full sec & $.331 *$ & -.251 & $.144^{*}$ & -.017 & .027 & -.017 \\
\hline $\mathrm{L}$ tert & .036 & -.085 & .025 & -.055 & .146 & -.053 \\
\hline $\mathrm{U}$ tert $^{1}$ & $.393 * *$ & $-.501 * *$ & $.163^{*}$ & $-.113^{*}$ & .159 & -.114 \\
\hline Never work & -.466 & -.210 & -.227 & -.047 & -.243 & -.032 \\
\hline Interm & .035 & .008 & .012 & .001 & .012 & .000 \\
\hline Prof. exec ${ }^{2}$ & .098 & .032 & .036 & .006 & .034 & .005 \\
\hline Female $^{3}$ & $-.366^{* * *}$ & $.364 * * *$ & $-.156 * * *$ & .080 & $-.146^{*}$ & .084 \\
\hline Age & -.019 & .005 & -.004 & .002 & -.005 & .002 \\
\hline $\operatorname{Age}^{\wedge} 2$ & .000 & .000 & .000 & .000 & .000 & .000 \\
\hline Intercept & $3.352 * * *$ & $3.967 * * *$ & $1.184 * * *$ & $1.371 * * *$ & $1.206^{* * *}$ & $1.369 * * *$ \\
\hline $\mathrm{R}^{\wedge} 2$ & $10.1 \%$ & $6.2 \%$ & $4.7 \%$ & $2.8 \%$ & $2.5 \%$ & $1.8 \%$ \\
\hline
\end{tabular}

Higher educational level has a positive (negative) impact on number of likes (dislikes). Being a woman has a negative (positive) impact. However, it is interesting that in the case of volume of dislikes, Poisson and negative binomial regression detected no impact of respondent's sex. Moreover, negative binomial regression detected no effect of educational level over volume of likes and dislikes. This could be explained by differences between 
methods to deal with count data. Under certain conditions, a negative binomial model is the most suitable for modelling this kind of dependent variable (Long, 1997). Linear and Poisson regression results are consistent between each other and provide support of an omnivorous trend. Higher education effectively motivates an increment to the number of likes and reduction of dislikes. However, these results are not consistent across different regression models.

\subsubsection{By Composition}

Van Rees, Vermunt and Verboord (1999) noted that 'omnivourism' should not only relate to the number of cultural preferences, but also to the combinatorial logic of them. The authors proposed the use of latent class analysis (LCA), which has become one of the standard techniques to test omnivourism. An LCA model assumes that based on response profiles, each individual belongs to one (and only one) of $\mathrm{k}$ non-observed classes or clusters. The amount of classes and the individual membership of classes is unknown and unobserved (Skrondal and Rabe-Hesketh, 2004). Independent variables could be used as explanatory variables in multinomial regression to test their impact. This kind of regression allows for the testing of the impact of independent variables over a nominal dependent variable with multiple categories (Long, 1997). An advancement on this is a combination of the two, known as the LCA MIMIC model (Skrondal and Rabe-Hesketh, 2004) that allows for the simultaneous detection of taste clusters and the quantification of the effect on them of stratification axes ${ }^{5}$. An omnivore by composition hypothesis can therefore be specified as:

$\boldsymbol{H}_{4}$ : In any society it is possible to detect a cohesive taste pattern group (most likely constituted by individuals holding higher social positions) that tends to prefer a combination of musical genres that cross cultural boundaries (van Rees et al., 1999; Chan and Goldthorpe, 2007a; Tampubolon, 2008b, 2010; Widdop and Cutts, 2012).

LCA is applied to indicators of musical taste recoded as categorical variables (like, neutral, dislike). The software used to fit the proposed model is Latent GOLD 4.5 (Vermunt and Magidson, 2008). An important assumption of LCA models is local dependency. This means that if judgment of musical genres is related among them, these associations have to be fully explained for the latent classes (Skrondal and Rabe-Hesketh, 2004). To deal with this, we included extra associations between pairs of taste indicators based on suggestions from Latent

\footnotetext{
${ }^{5}$ For instance García-Álvarez, Katz-Gerro and López-Sintas (2007), Tampubolon (2008a, b, 2010), Jaeger and Katz-Gerro (2010), Widdop and Cutts (2012).
} 
Gold 4.5 estimated bivariate residuals (Vermunt and Magidson, 2008). The same was done for the LCA MIMIC model. Consistent with previously detected tensions, it is possible to conclude that the best model is one of four latent classes ${ }^{6}$. The largest group detected, $\boldsymbol{L C A}_{\mathbf{1}}$ (47.3 percent), again prefers classical and to a lesser extent country and western while rejecting forms of popular music. A second group detected, whose members like urban and to a lesser extent electronic and world music, is labelled $\boldsymbol{L C A}_{\mathbf{2}}$ (15.4 percent). A third group, $\boldsymbol{L C A}_{3}$ (31 percent), shows a preference for the greatest number of genres, including rock, classical, and heavy metal and to a lesser extent modern jazz, world and urban music. Members of this group display patterns of preference consistent to the omnivore by composition. Finally, a fourth group $\boldsymbol{L C} \boldsymbol{A}_{4}$ (6.2 percent) represents a concentration of neutral opinions of rock, classical, and electronic genres, and dislike of what the $\boldsymbol{L C} \boldsymbol{A}_{\mathbf{2}}$ and $\boldsymbol{L C} \boldsymbol{A}_{\mathbf{1}}$ group members like.

Table Error! No text of specified style in document..3 Omnivore by composition multinomial regression.

\begin{tabular}{|c|c|c|c|}
\hline & $\begin{array}{c}L C A_{1} \text { vs. } L C A_{3} \\
(\boldsymbol{\beta}) \\
\end{array}$ & $\begin{array}{c}L C A_{2} \text { vs. } L C A_{3} \\
(\boldsymbol{\beta})\end{array}$ & $\begin{array}{c}L C A_{4} \text { vs. } L C A_{3} \\
\quad(\boldsymbol{\beta}) \\
\end{array}$ \\
\hline Sec bas/int & -.046 & -.104 & -.736 \\
\hline Full sec & -.200 & $-.720 *$ & -.527 \\
\hline L tert & -.401 & $-.792 *$ & -.428 \\
\hline U tert ${ }^{1}$ & $-.663^{*}$ & $-1.218 * *$ & -.918 \\
\hline Never work & 1.359 & .828 & $2.683 * *$ \\
\hline Interm & .053 & -.059 & .262 \\
\hline Prof. exec ${ }^{2}$ & .173 & .025 & -.428 \\
\hline Female $^{3}$ & $.835^{* * *}$ & $.961 * * *$ & $.746 * *$ \\
\hline Age & .033 & $-.157 * * *$ & .016 \\
\hline $\mathrm{Age}^{\wedge} 2$ & .000 & .001 & .001 \\
\hline Intercept & $-2.438 * *$ & 3.548 & $-4.243 * *$ \\
\hline $\mathrm{R}^{\wedge} 2$ & $22.3 \%$ & & \\
\hline
\end{tabular}

A multinomial regression is then applied, using as a dependent variable the previously obtained classification of taste groups (Table 2.3). In this model, the $\boldsymbol{L C A}_{\mathbf{3}}$ group is used as the reference category. Education, gender and age have significant impacts on explaining differences between taste groups. The $\boldsymbol{L C} \boldsymbol{A}_{\mathbf{1}}$ group tends to contain adults (over 55 years old) and respondents with low educational levels. As demonstrated above, tension exists between these and the $\boldsymbol{L} \boldsymbol{C} \boldsymbol{A}_{2}$ group, composed primarily of young (less than 35 years old), women and

\footnotetext{
${ }^{6}$ The decision was made focused on widely accepted criteria, such as lowest Bayesian information criterion (BIC), lowest percentage of misclassification, moderate bivariate residuals, and ease of interpretation (Vermunt and Magidson, 2008).
} 
respondents with secondary level education and low social class. $\boldsymbol{L C A}_{\mathbf{4}}$ members are mostly adults (over 65 years old), with a low educational attainment and from a lower social class. $\boldsymbol{L} \boldsymbol{C} \boldsymbol{A}_{3}$ are mainly young and middle-aged (25 to 54 years old), men, with a high education level and social class. These taste groups are consistent with those previously detected through MCA and cluster analysis. Despite small differences in preferences and rejections that define groups, using both techniques it is possible to conclude that these groups occupy the same social positions. Therefore, again it is possible to demonstrate mixed evidence of omnivourism and homology.

Replicating the LCA MIMIC approach proposed by Tampubolon (2008a, b) it is assumed that indicators of musical taste are ordinal scales. Due to the sparseness of data, which might produce highly biased estimate parameters, we use an alternative estimation method, namely, maximum a posteriori estimation (Galindo-Garre and Vermunt, 2006). Based on similar criteria to those used in the previous model, a five-cluster solution was selected, explaining 40.8 percent of entropy variance. Across all analyses we find a group with distinctive intense like for electronic and rock, and extreme dislike of country and western, jazz, heavy metal and classical music. We label this group as $\boldsymbol{M I M I C}_{\mathbf{1}}$ (11.3 percent). Members of the $\boldsymbol{M I M I C}_{\mathbf{2}}$ group (21.5 percent) have the highest overall levels of intermediate opinions and 'do not know' answers. This group reveals a preference only for classical and country and western music. The $\boldsymbol{M I M I C}_{\mathbf{3}}$ group (21.3 percent) reveals preferences for classical and to a lesser extent country and western. Members also display the strongest dislike for every other genre. Our fourth group, MIMIC $_{4}$ (23.4 percent), highlights its taste for rock, jazz, and classical music, along with intense dislike of electronic, urban, country and western, and world music.

Important to note is that this group displays lower levels of distaste for heavy metal. $\boldsymbol{M I M I C}_{\mathbf{5}}$ (22.5 percent) displays a strong like of rock and urban, while its members' views on world music and jazz are neutral. Moreover, this group expresses, as the cultural omnivore framework predicts, high levels of acceptance of heavy metal, world, electronic and classical music but a strong dislike of country and western.

Table Error! No text of specified style in document..4. Omnivore by composition: LCA MIMIC multinomial regression (effect coding).

\begin{tabular}{cccccc}
\hline & $M I M I C_{1}(\boldsymbol{\beta})$ & $\operatorname{MIMIC}_{2}(\boldsymbol{\beta})$ & $\operatorname{MIMIC}_{3}(\boldsymbol{\beta})$ & $\operatorname{MIMIC}_{4}(\boldsymbol{\beta})$ & $\operatorname{MIMIC}_{5}(\boldsymbol{\beta})$ \\
\hline Intercept & $10.787^{*}$ & -6.636 & -9.505 & .531 & 4.823
\end{tabular}




\begin{tabular}{cccccc} 
No educ & .477 & .593 & .525 & $-.732 *$ & $-.862 * *$ \\
Sec bas/int & $.970 * * *$ & $-.910^{*}$ & $-.581^{*}$ & .245 & .277 \\
L tert & -.090 & -.278 & -.311 & .508 & .170 \\
Full sec & -.549 & .479 & .150 & -.211 & .131 \\
U tert & $-.808^{*}$ & .115 & .217 & .190 & .285 \\
Working cl & -.144 & -.298 & -.177 & -.545 & 1.164 \\
Interm & -.272 & -.789 & -.342 & -.257 & 1.659 \\
Prof. exec & -.229 & -1.042 & -0690 & .045 & 1.916 \\
Never worked & .645 & 2.128 & 1.209 & .757 & -4.739 \\
Male & -.297 & -.318 & $-.338 *$ & $.268 *$ & $.685 * * *$ \\
Female & .297 & .318 & $.338^{*}$ & $-.268 *$ & $-.685 * * *$ \\
Age & $-.375 *$ & .181 & .214 & .103 & -.123 \\
Age^2 & .002 & $-4 . \mathrm{E}-04$ & $-3 . \mathrm{E}-04$ & -.002 & .000 \\
\hline Sig levels: $* \mathrm{p}<0.05, * * \mathrm{p}<0.01, * * * \mathrm{p}<0.001$ (two tailed tests) &
\end{tabular}

Results from the regression part of the model show that all variables (with the exception of social class) are statistically significant (Table 2.4). In addition, inspecting conditional probabilities (not shown), it is possible to again confirm that $\boldsymbol{M I M I C}_{\mathbf{1}}$ tend to be of a younger age cohort than the rest. $\mathbf{M I M I C}_{\mathbf{4}}$ and $\mathbf{M I M I C}_{\mathbf{5}}$ share a higher social class and education; $\boldsymbol{M I M I C}_{5}$ are predominately males. $\boldsymbol{M I M I C}_{2}$ and interestingly $\boldsymbol{M I M I C}_{3}$ are characterised as less educated and from a lower social class. The former are more likely to be adults while the latter elderly. In this context, this model distinguishes between $\mathbf{M I M I C}_{5}, \mathbf{M I M I C}_{\mathbf{3}}$ and a group of purely more traditional taste $\left(\boldsymbol{M I M I C}_{\mathbf{4}}\right)$. A number of groups display limited likes and broad dislikes. These are found both in the highest and the lowest social hierarchy, a result that is consistent with the homology thesis. $\mathbf{M I M I C}_{\mathbf{5}}$ are able to cross cultural boundaries among groups, but due to their unclear strong preferences it is not possible to relate this group to any of the traditional definitions of omnivourism. To refine the search for taste and distaste groups, neutral opinions (and in particular intermediate likes and dislikes) have to be examined. Therefore, we conclude there is partial evidence of omnivourism by volume and composition.

In an alternative setting, Bryson (1997) fitted logistic regressions for each genre using dislike as the dependent variable, and infers effects of sociodemographic variables counting the number of significant effects across them. A similar procedure but based on an analysis of the liking of musical works is performed by Savage (2006). However, authors do not conceptualise omnivores or univores in any specific way. Purhonen, Gronow and Rahkonen (2010) test omnivourism by composition, defined as whether respondents simultaneously display taste for low, middle and highbrow genres. These categories are constructed based on 
ratios of legitimacy defined in terms of the educational level of respondents. Dichotomic variables for each combination of taste are then used as dependent variables in logistic regressions. Therefore, a second omnivore by composition hypothesis is:

$\boldsymbol{H}_{5}$ : The higher the respondents' social position, the more likely they are to display a taste pattern that combines musical genres which cross low to highbrow cultural boundaries (Savage, 2006; Purhonen et al., 2010).

Table Error! No text of specified style in document..5. Omnivore by composition logistic regressions.

\begin{tabular}{cccccccc}
\hline & $\begin{array}{c}\text { legitimate } \\
\text { taste }(\boldsymbol{\beta})\end{array}$ & $\begin{array}{c}\text { Common } \\
\text { taste }(\boldsymbol{\beta})\end{array}$ & $\begin{array}{c}\text { Unauthorize } \\
\mathrm{d} \text { taste }(\boldsymbol{\beta})\end{array}$ & $\begin{array}{c}\text { Leg-comm- } \\
\text { unauth taste } \\
(\boldsymbol{\beta})\end{array}$ & $\begin{array}{c}\text { Legitimate- } \\
\text { common } \\
\text { taste }(\boldsymbol{\beta})\end{array}$ & $\begin{array}{c}\text { Legitimate- } \\
\text { unauth }(\boldsymbol{\beta})\end{array}$ & $\begin{array}{c}\text { Common- } \\
\text { unauth taste } \\
(\boldsymbol{\beta})\end{array}$ \\
\hline Sec bas/int & $.572 * *$ & -.203 & $-.462 *$ & -.092 & .171 & .115 & $-.374 *$ \\
Full sec & $1.079 * * *$ & .336 & $-.764 * *$ & .248 & $.726 * *$ & .295 & -.331 \\
L tert & $.866 * * *$ & .243 & -.251 & .460 & .459 & $.589 *$ & .082 \\
U tert & $1.522^{1} * * *$ & $.462 *$ & $-.739 * *$ & $.619 *$ & $1.124 * * *$ & $.657 * *$ & -.302 \\
Never work & -.118 & -.196 & $-1.239 * *$ & -1.482 & -.463 & -1.241 & -.662 \\
Interm & .052 & .133 & -.101 & -.096 & -.016 & .065 & .100 \\
Prof. exec & $.390 *$ & .214 & -.220 & -.245 & .162 & .002 & .021 \\
Female & .032 & $-.681 * * *$ & -.015 & -.093 & -.178 & .022 & $-.343 * *$ \\
Age & $.090^{2} * *$ & $.063 * *$ & $-.122 * * *$ & $.073 * *$ & $.136 * * *$ & .042 & -.039 \\
Age $^{\wedge} 2$ & $-4 \mathrm{E}-04 *$ & $-.001 * * *$ & $.001 * * *$ & $-.001 * *$ & $-.001 * * *$ & .000 & $1.276 \mathrm{E}-05$ \\
Intercept $^{2}$ & $-4.534 * * *$ & .254 & $4.422 * * *$ & $-3.426 * * *$ & $-4.726 * * *$ & $-3.141 * * *$ & $1.812 * * *$ \\
\hline $\mathrm{R}^{\wedge} 2$ & $16.5 \%$ & $16.9 \%$ & $5.7 \%$ & $2.8 \%$ & $8.5 \%$ & $6.4 \%$ & $8.7 \%$ \\
\hline
\end{tabular}

Ref. cats: 1: No educational qualifications; 2: working class; 3: Male.

Sig levels: $* \mathrm{p}<0.05, * * \mathrm{p}<0.01, * * * \mathrm{p}<0.001$ (two tailed tests)

Finally, logistic regressions using 'having or not' each of these taste patterns and their combinations as binary dependent variable are fitted (table 2.5). Logistic regression can be seen as a special case of multinomial regression, where the dependent variable has only two categories (Long, 1997). Significant estimated parameters indicate that males tend to display common and common-unauthorised patterns of taste. Age has a positive (declining) impact on probability of displaying legitimate and common taste, but is negative (declining) in terms of unauthorised patterns of taste. The younger age cohort tends to prefer unauthorised taste, older respondents common and legitimate taste. Individuals with a higher level of education tend to have legitimate and common tastes; respondents with low educational attainment tend to have unauthorised taste. This is consistent with the homology thesis. Moreover, respondents who are middle-aged and have higher levels of education display all three patterns of taste, as omnivourism by composition presupposes. There is of course the possibility that they might be influenced by how taste patterns are defined in terms of the 
educational level of the respondents that prefer them. For example, when the pattern includes classical music, we see the effect of university education and when it includes unauthorised music, the effect of low education.

\subsection{Conclusion}

It is possible to note that through the analyses performed, the conclusions extracted are consistent. They offer supportive evidence for the hypotheses they are intended to test, and at the same time they could be used to test others. These results concur with some of the peculiarities of the English data (Bennett et al., 2009, particularly Chapter 5). Not surprisingly, age is the primary stratifying factor of musical tastes and distastes, highlighting the distinction between popular music preferred by the younger age cohorts (urban and electronic), and the classical or traditional music of the older age groups, both reinforced by educational level and social class. Using every technique we detected a group that tends to like more music, or at least to choose two or more genres that cross cultural boundaries $\left(\boldsymbol{M C A}_{3}, \boldsymbol{L C A _ { 3 }}\right.$ and $\left.\boldsymbol{M I M I C _ { 5 }}\right)$. Although age and education are the most important variables we can use to distinguish groups of musical taste, class and taste are still strongly associated. Individuals belonging to these groups are likely to be in an advantageous position, that is, one which allows access to and the potential to know broadly about culture. In this regard we concur with arguments about cultural openness and the boundary crossing of some social groups, where is possible to detect omnivourism as a manifestation of cultural homology in the classic Bourdieusian sense, as previous research confirms (Tampubolon, 2008a; Bennett et al., 2009; Coulangeon and Lemel, 2010a, b; Lizardo and Skiles, 2012). Savage and Gayo (2011) argue that tensions in the musical field are not clearly distinguished by low and highbrow hierarchy, but they may be better defined between people who know and like a broader variety of music and those with more reduced command. The authors extend the search for omnivourism by analysing a different set of indicators from CCSE data which simultaneously measure taste and knowledge of specific musical works. An expert therefore, as an alternative concept to Peterson's cultural omnivore, is someone who, thanks to the possession of competences is able to express positive or negative judgment in regards to a broad range of musical works. We agree with the motivation of Savage and Gayo (2011), and although our analysis used different indicators, tensions detected among taste groups are consistent with their overall results.

Results from classification techniques (MCA and cluster analysis, LCA and MIMIC LCA) appear to be highly consistent. Moreover, association between grouping techniques measured 
through contingency index is 0.788 between MCA and LCA, 0.687 between MCA and MIMIC, and 0.718 between MIMIC and LCA. These become clearer when we compare

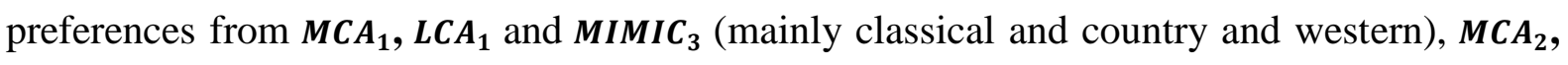
$\boldsymbol{L C A}_{2}$ and $\boldsymbol{M I M I \boldsymbol { C } _ { 1 }}$ (mainly urban and electronic), and $\boldsymbol{M C A}_{4}, \boldsymbol{L C A}_{4}$ and $\boldsymbol{M I M I \boldsymbol { C } _ { 2 }}$ (a high proportion of neutral opinions). Differences can be explained by their different theoretical constructions and data processing methods. The most notable difference between outcomes occurs between MIMIC and other techniques. Analysing gradational scales of preferences (and moreover, with additional information from covariates), the MIMIC model is the only technique able to detect a group whose taste combines genres which can be related to what is today considered highbrow music (classical, jazz and rock) (Savage, 2006; Bennett et al., 2009) and whose members are from a higher social position (MIMIC $\boldsymbol{C}_{\mathbf{4}}$ ). Solutions with a different number of clusters were tested using MCA and LCA, and it was not possible to detect a group with similar composition. Despite similitude and differences among techniques it is important to highlight that individuals belonging to specific clusters or classes does not necessarily imply that they simultaneously possess the same preferences but that they are likely to share similar taste and distaste as defined by a combination of genres ${ }^{7}$.

Now that we have determined that techniques deliver highly consistent results and that they can be used to simultaneously test homology and omnivourism, we consider their advantages and disadvantages. First, MCA has the advantage of being an exploratory technique where results are summarised in the form of intuitive and easy-to-read maps, which makes it ideal to quickly identify interdependencies between indicators and sociodemographic variables. In addition, cluster analysis of retained dimensions makes it possible to detect the existence of grouped patterns in the same way as LCA. Usefulness of regression models depends on the hypothesis to be tested. An analysis of number of likes or dislikes does not seem to provide other information than evidence of global trends of omnivourism by volume; furthermore, results depend on the type of regression used. For more sophisticated dependent variables, such as predefined patterns of taste, logistic regressions deliver results consistent with other analyses. This procedure has as an advantage its easiness, wide availability in statistical packages and extensively validated in the literature. LCA has the advantage of defining groups based on a probabilistic framework from latent variable modelling (Skrondal and Rabe-Hesketh, 2004). Moreover, the MIMIC model can simultaneously estimate the impact of sociodemographic variables in the construction of latent classes. Through these techniques

\footnotetext{
${ }^{7}$ Special thanks to the anonymous referee who pointed out this.
} 
it is possible to study both hypotheses of homology and omnivorism. A disadvantage is the complexity of these techniques compared to others, where statistical assumptions and data requirements might negatively influence final results, and sometimes it is not possible to obtain a solution because of the difficult convergence of complex models ${ }^{8}$. Despite this, the MIMIC model is able to recognise a previously undistinguishable taste group. We do not believe however that there is a perfect method to test one perspective or another; rather, there are several alternatives that may vary according to research questions, operationalisations of concepts, and data constraints. Moreover, these methods are complementary.

Among the limitations of this research we notice that the reduced number of analysed indicators from only one particular cultural domain might influence results and conclusions. Also, we did not focus in depth on the violation of statistical assumptions, inclusion of interactions on regression models, treatment of missing values or other more sophisticated improvements to reviewed techniques. These might indeed have an important impact on the construction of more elaborated hypotheses, and subsequent results and interpretations. This research intended to illustrate how theory and methods are related in the sociology of taste and cultural consumption. As van Meter (2003) argues, comparing results from two or more methods is the only way to be sure our results and further interpretations are not influenced by methodological choices. Although certain theoretical assumptions might seem built to adapt to methods, we argue that the operationalisation of cultural stratification should not be limited by methods, but that methods should accurately translate the theories they seek to empirically demonstrate. Each technique has its own advantages and disadvantages, and a good statistical analysis should detect overall data trends and response patterns, regardless of the sets of tools used.

\section{Funding}

This work was supported by the Economic and Social Research Council, North West Doctoral Training Centre $+3 \mathrm{PhD}$ award [grant number ES/J500094/1].

\section{Acknowledgements}

I would like to thank Gindo Tampubolon and Paul Widdop for their generous help. In addition, I am very grateful to Jukka Gronow, Tally Katz-Gerro, Semi Purhonen and Alan Warde for their valuable comments and suggestions on previous versions of the manuscript

\footnotetext{
${ }^{8}$ The vast majority of researchers reviewed in the literature do not mention how they dealt with the assumption of local dependency; it is plausible therefore to assume they did not do anything, and highly likely that these studies conclude that more latent classes exist than actually do.
} 
as well as to anonymous reviewers of BMS. Special thanks to Frances Hunt for helping to prepare and edit the manuscript. I alone am responsible for any errors and misinterpretations.

Notes

1. Exceptions are the application of EM algorithm and multiple imputation found in Tampubolon (2008a, b, 2010).

2. No education: CASMIN 1a+1b; Secondary basic/intermediate: CASMIN 1c+2a+2b; Secondary complete: CASMIN $2 \mathrm{c}$ vocational $+2 \mathrm{c}$ general; Lower tertiary: CASMIN 3a; Upper tertiary: CASMIN 3b (Brauns, Scherer and Steinmann, 2003).

3. For a comprehensive theoretical review of the subject see Peterson (2005), Bennett et al. (2009), Warde and Gayo-Cal (2009) and Coulangeon and Lemel (2010).

4. "...both the generative principle of objectively classifiable judgments and the system of classification (...) of these practices. It is in the relationship between the two capacities which define the habitus, the capacity to produce classifiable practices and works, and the capacity to differentiate and appreciate these practices and products (taste), that represented social world..." (Bourdieu, 1984:170).

5. For instance Garcia-Alvarez, Katz-Gerro and Lopez-Sintas (2007), Tampubolon (2008a, b, 2010), Jaeger and Katz-Gerro (2010), Widdop and Cutts (2012).

6. The decision was made focused on widely accepted criteria, such as lowest Bayesian information criterion (BIC), lowest percentage of misclassification, moderate bivariate residuals, and ease of interpretation (Vermunt and Magdison Magidson, 2008).

7. Special thanks to the anonymous referee who pointed out this.

8. The vast majority of researchers reviewed in the literature do not mention how they dealt with the assumption of local dependency; it is plausible therefore to assume they did not do anything, and highly likely that these studies conclude that more latent classes exist than actually do.

\section{References}

Bennett T, Savage M, Silva EB, Warde A, Gayo-Cal M and Wright D (2009) Culture, Class, Distinction. London: Routledge.

Bourdieu P (1984) Distinction - A Social Critique of the Judgement of Taste [Translated by Richard Nice]. London: Routledge. 
XX Not cited in the text Bourdieu P (1896) The forms of capital. In: Richardson JG (ed) Handbook of Theory and Research for the Sociology of Education. New York: Greeenwood, pp.241-258.

Bourdieu P and Wacquant JDL (1992) An Invitation to Reflexive Sociology. Cambridge: Polity Press.

Brauns H, Scherer S and Steinmann S (2003) The CASMIN Educational Classification in International Comparative Research. In: Hoffmeyer-Zlotnik JHP and Wolf C (eds) Advances in Cross - national Comparison - A European Working Book for Demographic and Socio economic Variables. London: Kluwer Academic/Plenum, 221-44.

Bryson B (1996) Anything but Heavy Metal. Symbolic Exclusion and Musical Dislikes. American Sociological Review 61(5): 884-99.

Bryson B (1997) What about the Univores? Musical Dislikes and Group-based Identity Construction among Americans with Low Levels of Education. Poetics 25(2-3): 141-56.

Chan TW and Goldthorpe JH (2007) Social Stratification and Cultural Consumption - The Visual Arts in England. Poetics 35(2-3): 168-90.

Coulangeon P and Lemel Y (2010) The Homology Thesis. Distinction Revisited. In: Robson K and Sanders C (eds) Quantifying Theory - Pierre Bourdieu. Berlin: Springer, 47-60.

Galindo-Garre F and Vermunt JK (2006) Avoiding Boundary Estimates in Latent Class Analysis by Bayesian Posterior Mode Estimation. Behaviormetrika 33(1): 43-59.

Garcia-Alvarez E, Katz-Gerro T and López-Sintas J (2007) Deconstructing Cultural Omnivorousness 1982-2002 - Heterology in Americans' Musical Preferences. Social Forces 86(2): 417-43.

IBM Corp (2011) IBM SPSS Statistics for Windows, Version 20.0. Armonk: IBM Corp. Jaeger MM and Katz-Gerro T (2010) The Rise of the Eclectic Cultural Consumer in Denmark 1964-2004. Sociological Quarterly 51(3): 460-83.

Lê S, Josse J and Husson F (2008) FactoMineR - An R Package for Multivariate Analysis. Journal of Statistical Software 25(1): 1-18.

Le Roux B and Rouanet H (2004) Geometric Data Analysis - From Correspondence Analysis to Structured Data Analysis. Berlin: Springer.

Lebaron F (2010) How Bourdieu 'Quantified' Bourdieu - The Geometric Modelling of Data. In: Robson K and Sanders C (eds) Quantifying Theory - Pierre Bourdieu. Berlin: Springer, 11-29.

Lizardo O and Skiles S (2012) Reconceptualizing and Theorizing "Omnivorousness" Genetic and Relational. Sociological Theory 30(4): 263-82. 
Long JS (1997) Regression Models for Categorical and Limited Dependent Variables. Thousand Oaks: Sage.

Peterson RA (1992) Understanding Audience Segmentation. From Elite and Mass to Omnivore and Univore. Poetics 21(4): 243-58.

Peterson RA (2005) Problems in Comparative Research. The Example of Omnivorousness. Poetics 33(5/6): 257-82.

Peterson RA and Simkus A (1992) How Musical Tastes Mark Occupational Status Group. In: Lamont M and Fournier M (eds) Cultivating Differences. Chicago: University of Chicago Press, 152-86.

Peterson RA and Kern RM (1996) Changing Highbrow Taste - From Snob to Omnivore. American Sociological Review 61(5): 900-07.

Purhonen S, Gronow J, and Rahkonen K (2010) Nordic democracy of taste? Cultural omnivorousness in musical and literary taste preferences in Finland. Poetics 38(3): 266-298.

R Core Team (2013) R - A Language and Environment for Statistical Computing. Vienna: Foundation for Statistical Computing.

Rouanet H, Ackermann W and Le Roux B (2000) The Geometric Analysis of Questionares. The Lessons of Bourdieu's la Distinction. Bulletin de Methodologie Sociologique 65(1): 5-18.

Savage M (2006) The Musical Field. Cultural Trends 15(2-3): 159-74.

Savage M and Gayo M (2011) Unravelling the Omnivore. A Field Analysis of Contemporary Musical Taste in the United Kingdom. Poetics 39(5): 337-57.

Skrondal A and Rabe-Hesketh S (2004) Generalized Latent Variable Modeling - Multilevel, Longitudinal, and Structural Equation Models. New York: Chapman \& Hall.

Tampubolon G (2008a) Distinction in Britain 2001-2004?. European Societies 10(3): 403-28.

Tampubolon G (2008b) Revisiting Omnivores in America Circa 1990s. The Exclusiveness of Omnivores? Poetics 36(2-3): 243-64.

Tampubolon G (2010) Social Stratification and Cultures Hierarchy among the Omnivores. Evidence from the Arts Council England Surveys. Sociological Review 58(1): 1-25.

Thomson K (2004) Cultural Capital and Social Exclusion Survey. Southampton: National Centre for Social Research.

Van Meter KM (2003) Interrelation between Type of Analysis and Type of Interpretation. Bern: Peter Lang.

Van Rees K, Vermunt J and Verboord M (1999) Cultural Classifications under Discussion Latent Class Analysis of Highbrow and Lowbrow Reading. Poetics 26(5-6): 349-65. 
Vermunt JK and Magidson J (2008) LG-Syntax Users Guide - Manual for Latent GOLD 4.5 Syntax Module. Belmont: Statistical Innovations Inc.

Warde A and Gayo-Cal M (2009) The Anatomy of Cultural Omnivorousness. The Case of the United Kingdom. Poetics 37(2): 119-45.

Warde A, Wright D and Gayo-Cal M (2007) Understanding Cultural Omnivorousness or the Myth of the Cultural Omnivore. Cultural Sociology 1(2): 143-64.

Warde A, Wright D and Gayo-Cal M (2008) The Omnivorous Orientation in the UK. Poetics 36(2-3): 148-65.

Widdop P and Cutts D (2012) Impact of Place on Museum Participation. Cultural Trends 21(1): 47-66. 